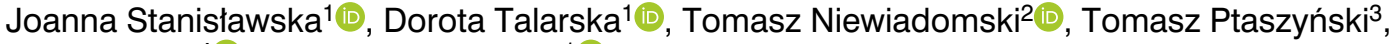
Mary Kalfoss ${ }^{4}$ (D), Magdalena Strugała ${ }^{1}$ (i)

${ }^{1}$ Department of Preventive Medicine, University of Medical Sciences, Poznań, Poland

${ }^{2}$ Orthopedics - Rehabilitational Clinical Hospital, University of Medical Sciences, Poznań, Poland

${ }^{3}$ Institute of Psychology, Faculty of Social Sciences, Adam Mickiewicz University

${ }^{4}$ Diakonova University College, Oslo, Norway

\title{
The functioning of patients on haemodialysis. Age as the main determinant of functional condition
}

\author{
Corresponding author: \\ Magdalena Strugała, Department \\ of Preventive Medicine, University \\ of Medical Sciences, Poznań, Poland, \\ e-mail: magdastrugal@ump.edu.pl
}

Medical Research Journal 2020; Volume 5, Number 4, 231-237 DOI: 10.5603/MRJ.a2020.0039 Copyright (C) 2020 Via Medica ISSN 2451-2591

\begin{abstract}
Introduction. Chronic kidney disease (CKD) is a progressive disease, and in spite of the progress of medicine, the care of specialized medical staff, and the patient's efforts, many of them develop its end-stage. The use of renal replacement therapy, haemodialysis, has provided patients with an opportunity to prolong their life, but due to complications, it leads to the deterioration in the quality of life.

Aim. To identify factors affecting the functioning of haemodialysis patients.

Materials and methods. The study involved 98 patients on haemodialysis, 37 women and 61 men. The average age was $59.65 \pm 15.51$ years. The research tool was the Barthel Index, IADL and ESAS-R scale, i.e. a scale of experiencing symptoms that may be associated with haemodialysis.

Results. The mean renal replacement therapy period was $42.76 \pm 50.30$ months. The most common cause of haemodialysis was chronic glomerulonephritis (21.43\%), diabetic nephropathy (18.37\%), polycystic kidney disease (12.24\%) and hypertensive nephropathy (9.18\%). In the study group, the average score on the Barthel Index scale was $90.10 \pm 14.82$, while the IADL score was $20.24 \pm 4.72$ points. Women showed a slightly higher ability in basic and complex daily living activities. People up to 60 years of age showed a slightly higher ability. According to the ESAS-R scale (7-10 points), fatigue and drowsiness were the most intense symptoms. People older than 60 years of age more often experienced pain $(p=0.048)$, malaise $(p=0.203)$, appetite disorders $(p=0.232)$, other problems $(p=0.042)$.

Conclusions. In spite of their older age, the patients showed quite good motor skills. The differences between men and women in the assessment of the severity of somatic symptoms slightly disappear in the elderly. Women showed a slightly higher ability in both basic and complex daily living activities. Older people experience more haemodialysis-related symptoms.
\end{abstract}

Key words: functional ability, haemodialysis

Med Res J 2020; 5 (4): 231-237

\section{Introduction}

Chronic kidney disease (CKD) is currently a serious health problem due to the ever-growing number of patients and the high risk of complications and death. It is estimated that ca. 600 million people around the world currently suffer from CKD, with about 4.2 million in Poland [1]. On the basis of the research carried out under the programs PoINef, POLSENIOR, NATPOL-11 and others, the frequency of occurrence of CKD in Poland is estimated at around $10 \%[2,3]$. As the incidence increases, the number of patients on haemodialysis is gradually increas- ing. Among patients with CKD, those on haemodialysis constitute 18\% in the United States, 13\% in Europe and Japan, and $56 \%$ in other parts of the world [4]. In developed countries, this percentage is gradually stabilizing, which may be partly due to the earlier detection of CKD and the implementation of nephroprotective activities [2, 5]. Chronic kidney disease, like any other chronic disease, affects the daily functioning of the patient, his or her social, professional and family life. They often face social and financial problems because the disease and the therapy associated with it do not allow them to maintain their professional activity. Many patients experience anxiety 
disorders, depression, and sleep disorders. In addition, nausea, malnutrition, dyspnoea, and severe somnolence occur, which further intensifies stress. Improving the mental condition of haemodialysis patients has a very positive effect on their physical condition [6-9]. Maintaining ability and independence is essential not only for the general well-being of patients and the effects of treatment, but it is also a significant factor in reducing the number of complications, recurrent hospitalizations, and even mortality in haemodialysis patients $[10,11]$. Haemodialyses additionally hinder the fulfilment of psycho-social needs, force changes in professional and, often, life plans, make the patient dependent on medical devices and pharmacotherapy $[6-8,12]$. Thus, functional dependence is a state of reduced physical ability in which a haemodialysis person is unable to perform tasks often considered basic in daily living.

Matching the choice of a renal replacement technique to the expectations of the patient alone undoubtedly contributes to the improvement of his or her functioning [14]. However, haemodialysis patients are characterized by varying degrees of functional ability compared to the general population [15]. Currently, an increasing level of functional activity in patients with ESRD is observed in both retrospective and prospective studies $[16,17]$.

Aim

To identify factors affecting the functioning of haemodialysis patients.

\section{Material and methods}

The sample consisted of 98 people treated with haemodialysis in two renal replacement therapy centres in the city of Poznań.

\section{Organization of the study}

The conduct of the study was approved in only 2 out of 4 centres offering haemodialysis treatment. Each time, patients were informed in detail about the purpose of the study, and its tools were discussed. Eventually, 105 people participated in the study, with 7 questionnaires being rejected due to missing answers or to patient withdrawal. The condition of participation in the study was the patient's consent, a psychophysical condition enabling the self-completion of questionnaires, and the absence of other debilitating diseases.

The study was conducted between February and June 2013.

Inclusion criteria:

- haemodialysis treatment for at least 6 months.

- no other significantly functionally debilitating conditions.

\section{Research tools}

1. A questionnaire for gathering demographic and clinical data

2. Barthel Index of Activities of Daily Living (Barthel Index) - a scale of 0 to 100 points. Patients with a score of above 86 are regarded in good functional condition, while a score below 20 means severe impairment.

3. Instrumental Activities of Daily Living Scale (IADL) - the version with 9 questions, with 3 options of answers was used: 1 point means full dependence, 2 points - partial dependence, and 3 - independence. Maximum total score is 27 points.

4. Edmonton Symptom Assessment System (revised edition) - ESAS-R.

The scale contains 10 questions about the severity of the experienced symptoms/ailments that can accompany haemodialysis: pain, fatigue, drowsiness, nausea, appetite, dyspnoea, depression, nervousness, the general feeling, other problems (e.g. constipation). The answer range is within 0 pts. - no ailments, above 10 pts. - maximum severity. Each symptom is analysed separately.

\section{Statistical analysis}

The analysis was performed using IBM SPSS Statistics. Differences between two independent groups were evaluated using the t-Student test or non-parametric Mann-Whitney test. Correlations were assessed using Spearman's $r_{s}$ rank correlation coefficient. Nominal variables were analysed using Pearson's chi-squared test. All the tests were considered statistically significant at $p<0.05$.

The two-factor analysis of variance was also applied. Age as a variable affecting the functioning of patients on haemodialysis was taken into account in each analysis, and the other variables were added to it.

Taking into account the average age of the respondents, further analyses were performed allowing for two age groups: up to 60 and over 60 years of age. Considering the mean dialysis period, two groups were distinguished, i.e. up to 48 months and above. Marital status was analysed in the groups: married, single (other people).

\section{Results}

\section{Demographics and clinical data}

There were 61 men (62.24\%) and 37 women (37.76\%) aged 18-85 in the study group. The average age was $59.65 \pm 15.51$ years. The median was 62 years.

In the study group, 67 people $(68.37 \%)$ were married. 12 people (12.24\%) lived alone mainly because of widowhood. $1 / 3$ of the group had graduated 
Table 1. Demographic and clinical data of the study group

\begin{tabular}{|c|c|c|c|c|c|c|}
\hline $\begin{array}{l}\text { Demographic } \\
\text { and clinical data }\end{array}$ & $\begin{array}{l}\mathrm{Ma} \\
\mathrm{No} . \\
61\end{array}$ & $\begin{array}{l}\text { ex } \\
{[\%]} \\
62.24\end{array}$ & $\begin{array}{l}\text { Fen } \\
\text { No. } \\
37\end{array}$ & $\begin{array}{c}\text { sex } \\
{[\%]} \\
37.76\end{array}$ & $\begin{array}{l}\text { Tota } \\
\text { No. } \\
98\end{array}$ & $\begin{array}{l}{[\%]} \\
100\end{array}$ \\
\hline \multicolumn{7}{|l|}{ Age } \\
\hline$<60$ years & 29 & 47.54 & 21 & 56.76 & 50 & 51.02 \\
\hline$>60$ years & 32 & 52.46 & 16 & 43.24 & 48 & 48.98 \\
\hline Average age & \multicolumn{2}{|c|}{$59.87 \pm 16.69$} & \multicolumn{2}{|c|}{$59.30 \pm 13.55$} & \multicolumn{2}{|c|}{$59.65 \pm 15.51$} \\
\hline \multicolumn{7}{|l|}{ Marital status } \\
\hline In a relationship & 46 & 46.94 & 21 & 21.43 & 67 & 68.4 \\
\hline Single & 10 & 10.20 & 5 & 5.10 & 15 & 15.3 \\
\hline Widowed & 2 & 2.04 & 10 & 10.20 & 12 & 12.2 \\
\hline Divorced & 3 & 3.06 & 1 & 1.02 & 4 & 4.1 \\
\hline \multicolumn{7}{|l|}{ Education } \\
\hline Primary & 11 & 11.22 & 8 & 8.16 & 19 & 19.39 \\
\hline Vocational & 16 & 16.33 & 16 & 16.33 & 32 & 33.67 \\
\hline Secondary & 25 & 25.51 & 10 & 10.20 & 35 & 35.71 \\
\hline Higher vocational (bachelor's degree) & 3 & 3.06 & - & & 3 & 3.06 \\
\hline Higher university (master's degree) & & & 3 & 3.06 & & \\
\hline \multirow[t]{2}{*}{ Academic title } & 5 & 5.10 & \multirow{2}{*}{\multicolumn{2}{|c|}{-}} & 8 & 8.16 \\
\hline & 1 & 1.02 & & & 1 & 1.02 \\
\hline \multicolumn{7}{|l|}{ Professional activity } \\
\hline Full-time employed & 3 & 3.06 & 1 & 1.02 & 4 & 4.08 \\
\hline Part-time employed & 1 & 1.02 & 1 & 1.02 & 2 & 2.04 \\
\hline Farmer & 4 & 4.08 & - & & 4 & 4.08 \\
\hline Retired & 31 & 31.63 & 18 & 18.37 & 49 & 50.00 \\
\hline Pensioner & 21 & 21.43 & 14 & 14.29 & 35 & 35.71 \\
\hline Student & 1 & 1.02 & - & & 1 & 1.02 \\
\hline Unemployed & - & & 3 & 3.06 & 3 & 3.06 \\
\hline \multicolumn{7}{|l|}{ Having children } \\
\hline Yes & 51 & & 29 & & 80 & 81.60 \\
\hline No & 10 & & 8 & & 18 & 18.40 \\
\hline \multicolumn{7}{|l|}{ Economic situation after falling ill } \\
\hline No change & 47 & 47.96 & 26 & 26.53 & 73 & 74.49 \\
\hline Better & 2 & 2.04 & 2 & 2.04 & 4 & 4.08 \\
\hline Worse & 12 & 12.24 & 9 & 9.18 & 21 & 21.43 \\
\hline \multicolumn{7}{|l|}{ Dialysis therapy period } \\
\hline up to 48 months & 48 & 78.69 & 27 & 72.97 & 75 & 81.63 \\
\hline above 48 months & 13 & 21.31 & 10 & 27.03 & 23 & 12.64 \\
\hline Average period & & & & & \multicolumn{2}{|c|}{$42.76 \pm 50.30$ months } \\
\hline
\end{tabular}

from high school (33.67\%) and vocational school (32.66\%). Retired people (50.00\%) constituted a half of the group, followed by another dominant group of pensioners $(35.71 \%)$. Only 6 people $(6.12 \%)$ worked professionally. 80 respondents (81.60\%) had children. 21 people $(21.43 \%)$ realized that their economic situation deteriorated after haemodialysis had been started. The mean renal replacement therapy period was $42.76 \pm 50.30$ months. The shortest period was 6 months, the longest 312 months (Tab. 1). The most common causes of haemodialysis included: chronic glomerulonephritis (21.43\%), diabetic nephropathy (18.37\%), polycystic kidney disease (12.24\%), and hypertensive nephropathy $(9.18 \%)$.

\section{Functional condition}

In the study group, the average Barthel Index score was $90.10 \pm 14.82$, while in IADL it was $20.24 \pm 4.72$ points. (Tab. 2). Women showed slightly higher, although statistically insignificant ability in terms of basic as well as complex daily living activities. In general, the group with an average of 59.65 years of age showed relatively good motor skills.

There was a statistically significant difference between age and self-dependence in basic and complex daily living activities $(p<0.05)$. People up to 60 years of age showed slightly higher ability. Despite the observed differences in the functioning of people depending on education, a statistically significant difference was found 
Table 2. Functional ability

\begin{tabular}{|c|c|c|}
\hline Variables & $\begin{array}{l}\text { Barthel Index } \\
\text { avg. pts. }\end{array}$ & $\begin{array}{l}\text { IADL } \\
\text { avg. pts. }\end{array}$ \\
\hline $\begin{array}{l}\text { Sex } \\
\text { Male } \\
\text { Female } \\
\text { Student's t-test } \\
\text { df } \\
\text { significance of } p\end{array}$ & $\begin{array}{c}89.6 \pm 14.6 \\
90.9 \pm 15.3 \\
-0.437 \\
96 \\
0.663\end{array}$ & $\begin{array}{c}20.3 \pm 4.7 \\
20.7 \pm 3.9 \\
-0.459 \\
96 \\
0.647\end{array}$ \\
\hline $\begin{array}{l}\text { Age } \\
<60 \text { years } \\
>60 \text { years } \\
\text { Student's t-test } \\
\text { df } \\
\text { significance of } p\end{array}$ & $\begin{array}{c}95.1 \pm 12.6 \\
84.9 \pm 15.3 \\
3.531 \\
96 \\
0.001\end{array}$ & $\begin{array}{c}22.3 \pm 3.3 \\
18.5 \pm 4.5 \\
4.829 \\
96 \\
0.000\end{array}$ \\
\hline $\begin{array}{l}\text { Education } \\
<\text { Secondary } \\
\text { Secondary and higher } \\
\text { Student's t-test } \\
\text { df } \\
\text { significance of } p\end{array}$ & $\begin{array}{c}87.5 \pm 16.4 \\
92.9 \pm 12.5 \\
1.736 \\
96 \\
0.060\end{array}$ & $\begin{array}{c}19.8 \pm 4.8 \\
21.1 \pm 3.8 \\
-1.446 \\
96 \\
0.151\end{array}$ \\
\hline $\begin{array}{l}\text { Marital status } \\
\text { Married } \\
\text { Single } \\
\text { Student's t-test } \\
\text { df } \\
\text { significance of } p\end{array}$ & $\begin{array}{c}90.4 \pm 14.0 \\
89.8 \pm 17.1 \\
-0.186 \\
96 \\
0.852\end{array}$ & $\begin{array}{c}20.3 \pm 4.3 \\
20.7 \pm 4.6 \\
0.412 \\
96 \\
0.681\end{array}$ \\
\hline $\begin{array}{l}\text { Dialysis period } \\
\text { up to } 48 \text { months } \\
>48 \text { months } \\
\text { Student's t-test } \\
\text { df } \\
\text { significance of } p\end{array}$ & $\begin{array}{c}89.5 \pm 15.6 \\
92.0 \pm 12.1 \\
-0.823 \\
96 \\
0.412\end{array}$ & $\begin{array}{c}20.2 \pm 4.6 \\
20.4 \pm 5.1 \\
0.356 \\
96 \\
0.722\end{array}$ \\
\hline
\end{tabular}

only in terms of IADL. People with higher education were more able and obtained higher scores in both the Barthel Index and IADL (Fig.1).

Having children significantly diversified the respondents' ability in basic daily living activities (Barthel Indext $=-2.122, d f=96, p=0.043)$. Childless patients showed higher ability (Fig. 2). However, having children did not diversify ability in terms of IADL $(\mathrm{t}=1.494$, $d f=96 p=0.139$ )

The two-factor analysis of variance was used to determine whether age and $\operatorname{sex}(F=0.298, p=0.586)$, age and education $(F=1.310, p=0.255)$, and age and the fact of having children $(F=2.329, p=0.130)$, diversify the level of self-dependence in terms of the Barthel Index. No difference between the analysed factors and the respondents' degree of ability was found. A detailed analysis showed that only age differentiates the state of ability in terms of basic daily living activities. In addition, as shown in Figures 1 and 2, in the group of older people, respondents with higher education and not having children showed higher levels of ability.

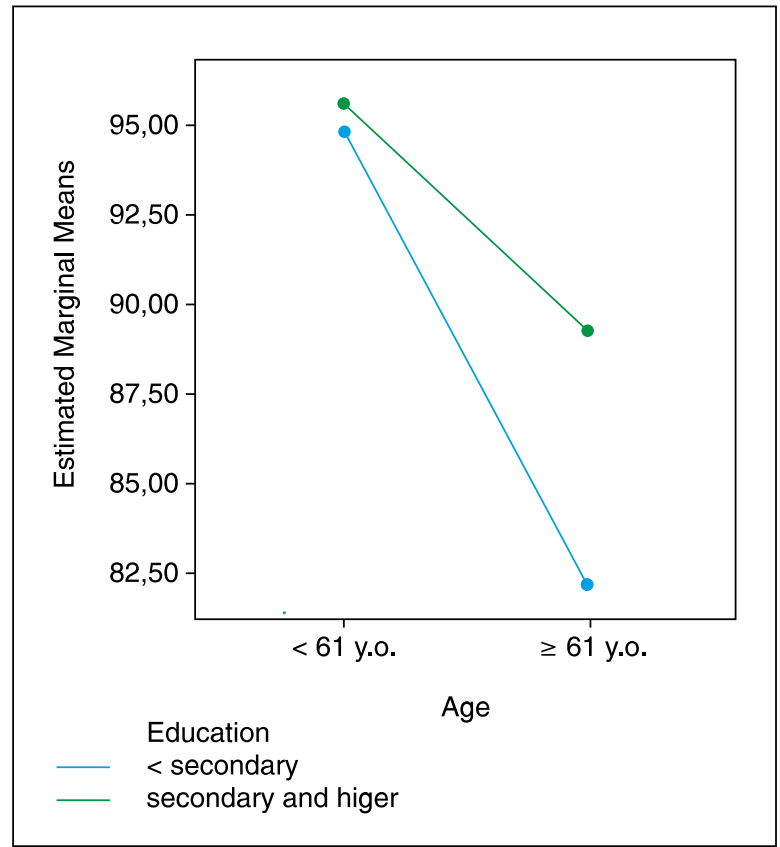

Figure 1. Estimated marginal means of index Barthel

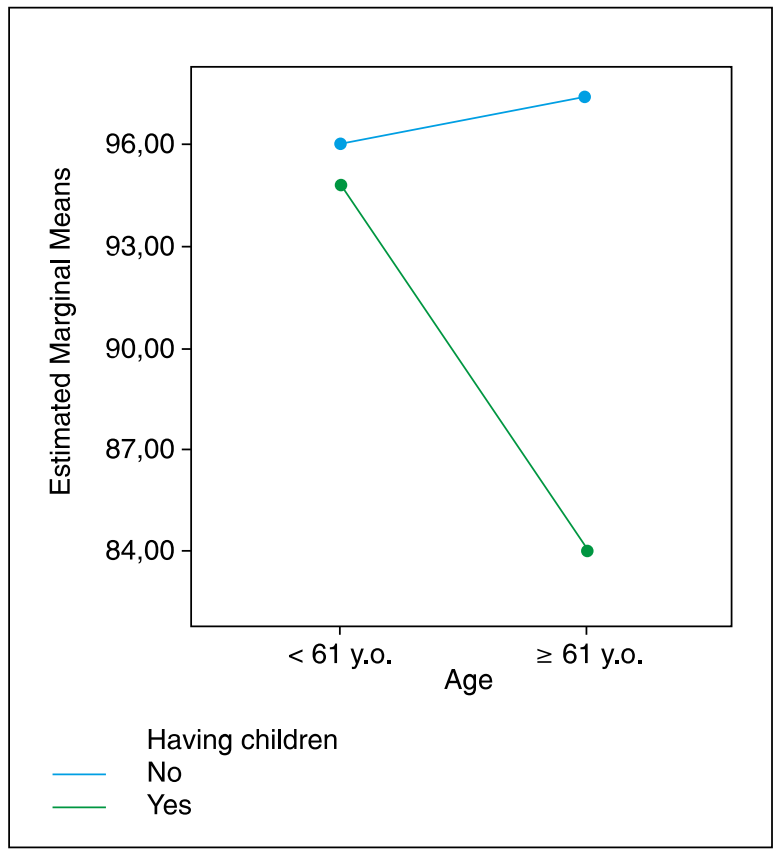

Figure 2. Estimated marginal means of index Barthel

\section{Assessment of symptom severity — ESAS-R scale}

Of the 10 analysed ailments, the most severe (7-10 points) included fatigue and drowsiness. These symptoms occurred with such intensity in $18.37 \%$ of the respondents. The least intensive symptoms were nausea (in 92.86\%), depression (in $84.69 \%$ ), 
Table 3. Assessment of symptom severity - ESAS-R scale

\begin{tabular}{|c|c|c|c|c|}
\hline ESAS-R areas & $\begin{array}{c}\text { sex* }^{\star} \\
\text { Correlation } \\
\text { coefficient and } \\
\text { significance level }\end{array}$ & $\begin{array}{c}\text { education** } \\
\text { Correlation } \\
\text { coefficient and } \\
\text { significance level }\end{array}$ & $\begin{array}{c}\text { age }{ }^{* * *} \\
\text { Correlation } \\
\text { coefficient and } \\
\text { significance level }\end{array}$ & $\begin{array}{l}\text { dialysis period**} \\
\text { Correlation } \\
\text { coefficient and } \\
\text { significance level }\end{array}$ \\
\hline Pain & $0.704 p=0.483$ & $0.953 p=0.343$ & $0.268 p=0.008$ & $0.205 p=0.043$ \\
\hline Fatigue & $0.705 p=0.483$ & $2.116 p=0.037$ & $0.194 p=0.056$ & $0.091 p=0.374$ \\
\hline Nausea & $-0.147 p=0.883$ & $0.500 p=0.618$ & $0.000 p=0.997$ & $0.000 p=0.999$ \\
\hline Depression & $-0.608 p=0.545$ & $-0.098 p=0.922$ & $-0.171 p=0.093$ & $0.149 p=0.143$ \\
\hline Anxiety & $-0.215 p=0.830$ & $0.047 p=0.963$ & $0.039 p=0.706$ & $0.322 p=0.001$ \\
\hline Somnolence & $0.293 p=0.770$ & $0.580 p=0.564$ & $0.120 p=0.241$ & $0.175 p=0.085$ \\
\hline Appetite & $-2.014 p=0.050$ & $2.098 p=0.039$ & $-0.217 p=0.032$ & $0.273 p=0.006$ \\
\hline General feeling & $-0.560 p=0.577$ & $2.003 p=0.048$ & $-0.113 p=0.267$ & $0.296 p=0.003$ \\
\hline Dyspnoea & $-1.419 p=0.161$ & $2.300 p=0.024$ & $-0.099 p=0.334$ & $0.269 p=0.007$ \\
\hline Another problem & $0.854 p=0.395$ & $-0.903 p=0.369$ & $0.284 p=0.005$ & $-0.077 p=0.451$ \\
\hline
\end{tabular}

* Student's t-test; ** Spearman's $\mathrm{r}_{\mathrm{s}}$ correlation coefficient; *** Pearson correlation

dyspnoea (in 83.67\%), and other problems, e.g. constipation (in $76.53 \%$ ). Taking into account sex (Tab. 3), a statistically significant difference in experiencing symptoms was found only in appetite disorders (Student's t-test $\mathrm{t}=-2.014$, $\mathrm{df}=96, \mathrm{p}=0.05$ ). More often the disorder occurred in women (M 24.59\%; F 32.43\%).

The respondents' age correlated with the experience of pain (Spearman's test $r=0.267, p=0.008$ ), appetite disorders $(r=-0.202, p=0.046)$, and other problems $(r=0.316, p=0.002)$. Older people experience more symptoms. Having children was statistically significantly related to feelings of fatigue (Student's t-test $\mathrm{t}=1.908$, df $=96, \mathrm{p}=0.059$ ) and nausea (Student's t-test $t=2.226, d f=96, p=0.028)$. Childless people experience these ailments to a lesser extent.

In addition, the level of education differentiated the feeling of fatigue ( $p=0.037$ ) and general feeling $(p=0.050)$. The duration of renal replacement therapy correlated with appetite $(p=0.006)$, dyspnoea $(p=0.007)$, and anxiety $(p=0.001)$. The longer the dialysis therapy period, the higher the severity of the symptoms (Tab. 3).

The two-factor analysis of variance showed no difference between the severity of the symptoms (average) and the age and sex of the patients analysed at the same time (Anova F 0.212 p > 0.646). However, it can be observed that differences between men and women in the assessment of the severity of somatic symptoms are slightly less pronounced in the elderly. The two-factor analysis did not show any differences in experiencing symptoms while at the same time taking into account age and education ( $\mathrm{F} 0.134 \mathrm{p}=0.716)$ and age having children (F1.094 $p=0.298)$ (Fig.3).

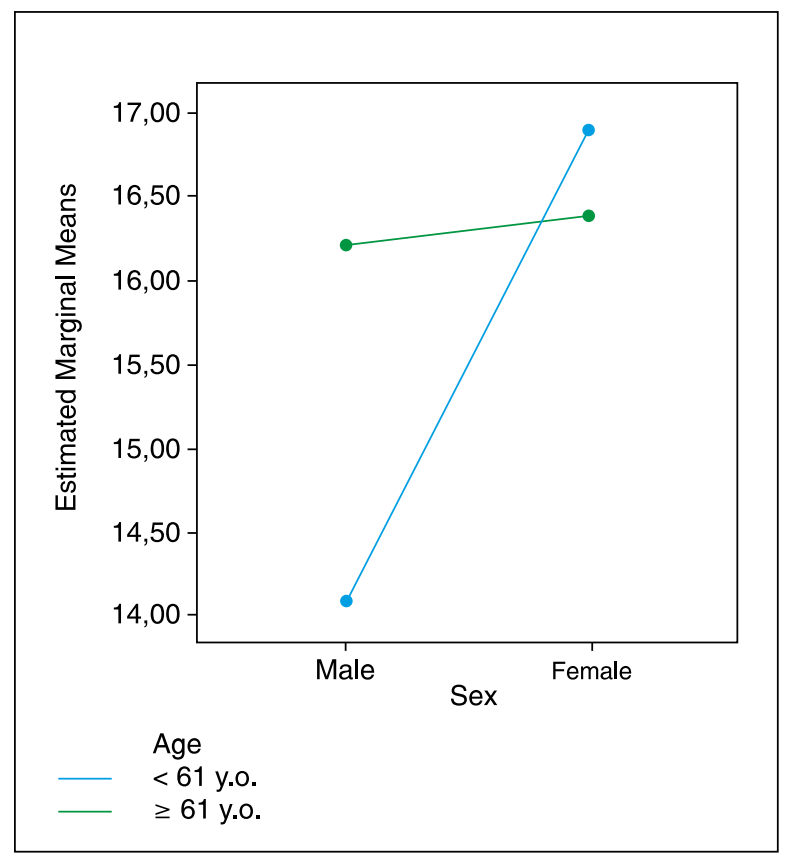

Figure 3. Estimated marginal means of ESAS SUM

\section{The ESAS-R scale and the functional condition}

Correlation between the ability to perform basic daily living activities (Barthel Index) and the severity of pain $(p=0.000)$, fatigue $(p=0.001)$, appetite $(p=0.009)$, general feeling $(p=0.009)$, other problems $(p=0.000)$ was confirmed using Spearman's $r_{s}$ correlation coefficient. Correlation between the independent performance of complex daily living activities (IADL), and the severity of ailments such as pain $(p=0.003)$, appetite $(p=0.009)$, general feeling $(p=0.034)$, the 
other problems $(p=0.000)$ was also confirmed using Spearman's $r_{s}$ correlation coefficient.

\section{Discussion}

Acceptance of the disease allows the patient to function properly despite the many dangers, limitations and problems associated with the loss of his or her health. Awareness of the causes and effects of the disease, as well as the knowledge of possible complications, allows patients' effective self-control and pro-health behaviour to improve the quality of, and prolong their lives [18]. Our survey showed the respondents' fairly good functional ability (Barthel Index 90.10 points, IADL 20.24 points). Similar results were obtained by Kapa-Skrzypczak et al., who claimed that 25 dialysis patients $(62.5 \%)$ declared their full ability to perform complex daily living activities (IADL) such as vacuuming, shifting a table, lifting or carrying shopping, bathing, and getting dressed. Only 4 respondents (10\%) required assistance in all housework activities, and 11 respondents $(27.5 \%)$ showed limited independence with regard to bathing and getting dressed [14]. A similar trend was observed by Jassal et al., who found that dialysis patients had full ability in using the telephone (91\%), in drug preparation and administration (84\%), and money management $(81 \%)$. The respondents required the most assistance in doing housework and laundry (21\%) [13]. It should be stressed that patients functional independence have been supported in other studies. The results from both our own research and from the cited studies show that patients with ESRD, who are more functionally able, are also generally younger, in better health, generally feel better, and are more likely to assess their disease better than those who are less functionally able [19-21].

Patients with chronic kidney disease aged 18-85, treated using haemodialysis, were included in our own study. The analysis of collected data confirmed that the respondents up to 60 years of age functioned better in terms of basic and complex daily living activities. Younger people, most often due to the shorter illness period and fewer complications, tend to be more satisfied with their health, especially in the somatic sphere [19-24]. The quality of life, health perception, and social relationships deteriorate with age [25]. Oliwier et al. [26] observed worse functioning $(p=0.000)$ and malaise $(p=0.005)$ already in a group slightly younger (54.71 \pm 14.12 years) than our respondents.

In our own study, the mean renal replacement therapy period was $42.76 \pm 50.30$ months. The largest group of 75 people (81.63\%) consisted of patients on haemodialysis for up to 48 months. The longer the dialysis period, the greater the severity of the symptoms, and the worse the functional ability. Similar results were obtained by other authors claiming that, during haemodialyses, the functional ability of patients with endstage renal disease deteriorates with time and with the occurrence of haemodialysis-related nuisances [27, 28].

Sex was not a significant determinant of the functional condition in our study. In other studies, women were less psycho-physically functional. They more often developed side effects of haemodialysis and showed lower mood, and more frequent fatigue [26].

The increased severity of experienced disease-related ailments and emotional lability are often the cause of a poorer assessment of the quality of life among women [29]. Also, haemodialysis patients who experience symptoms of depression and anxiety more often assess their quality of life worse and demonstrate poorer functioning $[30,31]$.

Authors of studies conducted in developing countries drew attention to the link between motor skills, sex, and the quality of life [29, 32]. Women also assessed their quality of life worse. Rarely undertaken social and motor activity, due to the lack of acceptance of the disease, was the most common cause of decreased quality of life as compared to men [25, 29, 33].

Another factor of importance in this study was the importance of education and having children. In the elderly group, higher levels of ability were reported by people with higher education and being childless. Links between functional ability and quality of life on the one hand, and education on the other, are confirmed in other studies [29, 34, 35]. For example, people with higher education assessed their quality of life generally better, which was associated with professional satisfaction, self-dependence and financial independence [34]. Zyoud et al. [29] also point out that people with higher education are better acquainted with the specific nature of the disease and its complications, which also results in a better relationship with the health care team.

Another factor of importance in this study were the types and severity of symptoms found in haemodialysis patients. The most common symptoms included fatigue and drowsiness, while nausea, depression, dyspnoea, and others, e.g. constipation, were the rarest. Older people suffered from more symptoms. Similar results were obtained by Kapka-Skrzypczak et al. [14]. In their study, the most common ailments were: pain (80\%), chronic fatigue $(67.5 \%)$, sleep disorders $(50 \%)$, diarrhoea or constipation (40\%), lack of appetite (40\%), vomiting (36.7\%), dyspnoea (15\%) [14]. However, other studies have shown that the physical symptoms of the disease, with the exception of chronic fatigue and drowsiness, are not significantly increased. The low severity of symptoms probably also affected better functional ability and resulted in a better understanding of the disease [36, 37]. Moreover, as documented by others, 
haemodialysis patients are more susceptible to stress, depression, and are more emotionally responsive than healthy people. Improving the mental condition of patients on haemodialysis has a positive effect on their physical condition [36, 38].

\section{Conclusions}

In spite of their older age, the patients showed good functional ability. Age was the main factor affecting the ability of the elderly in terms of basic and complex daily living activities. Women and, in the group of older people, also patients with higher education and having children, showed slightly higher ability in terms of basic as well as complex daily living activities. Older people experience more haemodialysis-related symptoms.

\section{References}

1. Wieliczko M, Kulicki P, Matuszkiewicz-Rowińska J. [Classification, epidemiology and etiology of chronic kidney disease]. Wiad Lek. 2014 67(3): 393-396, indexed in Pubmed: 25782195

2. Rutkowski B. Przewlekła choroba nerek - problem nie tylko medyczny, ale także socjoekonomiczny. Post N Med. 2009; 10: 817-822.

3. Rutkowski B, Król E. Epidemiology of chronic kidney disease in central and eastern europe. Blood Purif. 2008; 26(4): 381-385, doi: 10.1159/000137275, indexed in Pubmed: 18535372.

4. ESRD patients in 2013. A global perspective. http://www.vision-fmc. com/ files/pdf_2/ESRD_Patients_2013.pdf

5. Tonelli M, Riella M. Chronic kidney disease and the aging population. Nephrol Dial Transplant. 2014; 29(2): 221-224, doi: 10.1093/ndt/gft519, indexed in Pubmed: 24493860.

6. Low J, Smith G, Burns A, et al. The impact of end-stage kidney disease (ESKD) on close persons: a literature review. NDT Plus. 2008; 1(2): 67-79, doi: 10.1093/ndtplus/sfm046, indexed in Pubmed: 28656996.

7. Jabłońska M, Lubas A, Niemczyk S. Quality of life in chronic kidney disease. Nefrol Dial Pol. 2016; 20: 205-211.

8. Rutkowski B. Highlights of the epidemiology of renal replacement therapy in Central and Eastern Europe. Nephrol Dial Transplant. 2006; 21(1): 4-10, doi: 10.1093/ndt/gfi251, indexed in Pubmed: 16280373.

9. Pluta A, Felsmann A, Faleńczyk K. Some health problems in the dialysis patient population and the share of nurses insolving tchem. Medycyna Rodzinna. 2014; 3: 128-132

10. Saad MM, El Douaihy Y, Boumitri C, et al. Predictors of quality of life in patients with end-stage renal disease on hemodialysis. Int J Nephrol Renovasc Dis. 2015; 8: 119-123, doi: 10.2147/IJNRD.S84929, indexed in Pubmed: 26366104.

11. Kurella Tamura M, Covinsky KE, Chertow GM, et al. Functional status of elderly adults before and after initiation of dialysis. N Engl J Med. 2009; 361(16): 1539-1547, doi: 10.1056/NEJMoa0904655, indexed in Pubmed: 19828531.

12. Cruz MC, Andrade C, Urrutia M, et al. Quality of life in patients with chronic kidney disease Clinics (Sao Paulo). 2011; 66 (6): 991-995 doi: 10.1590/s1807-59322011000600012, indexed in Pubmed: 21808864.

13. Jassal SV, Karaboyas A, Comment LA, et al. Functional Dependence and Mortality in the International Dialysis Outcomes and Practice Patterns Study (DOPPS). Am J Kidney Dis. 2016; 67(2): 283-292, doi: 10.1053/j.ajkd.2015.09.024, indexed in Pubmed: 26612280

14. Kapka-Skrzypczak L, Lipin B, Niedźwiecka J, et al. Subjective assessment of quality of life of dialysis patients by peritoneal dialysis and hemodialysis. Probl Hig Epidemiol. 2012; 93(4): 790-797.

15. O'Lone E, Connors M, Masson P, et al. Cognition in People With End-Stage Kidney Disease Treated With Hemodialysis: A Systematic Review and Meta-analysis. Am J Kidney Dis. 2016; 67(6): 925-935, doi: 10.1053/j.ajkd.2015.12.028, indexed in Pubmed: 26919914.

16. Stewart AL, Hays RD, Ware JE. Methods of validating MOS health Measures. In: Stewart AL, Ware JE. ed. Measuring functioning and well-being: the medical outcomes study approach. Duke University Press, Durham, NC 1992: 309-324.
17. Saby A, Miller LS. Functional Assessment in End-Stage Renal Disease: Enhancing Quality of Life. Semin Dial. 2016; 29(2): 170-172, doi: 10.1111/sdi.12466, indexed in Pubmed: 26756940

18. Basińska MA, Waraksa-Wiśniewska M, Andruszkiewicz A. Nastrój jako wyznacznik akceptacji choroby pacjentów dializowanych. Nefrol Dia Pol. 2014; 18: 27-31.

19. Aghakhani N, Sharif Nia H, Samad Zadeh S, et al. Quality of life during hemodialysis and study dialysis treatment in patients referred to teaching hospitals in Urmia-Iran in 2007. Caspian J Intern Med. 2011 2(1): 183-188, indexed in Pubmed: 24024012.

20. Boudreau JE, Dubé A. Quality of life in end stage renal disease: a concept analysis. CANNT J. 2014; 24(1): 12-20, indexed in Pubmed: 24783768 .

21. Gentile S, Jouve E, Dussol B, et al. Development and validation of a French patient-based health-related quality of life instrument in kidney transplant: the ReTransQoL. Health Qual Life Outcomes. 2008; 6: 78, doi: 10.1186/1477-7525-6-78, indexed in Pubmed: 18851730

22. Kocka K, Grabowska K, Bartoszek A, et al. Impact of socio-demographical factors on qualityof life of patients treated with haemodialysis. Hygeia Public Health. 2016; 51(1): 82-86.

23. Muszalik M, Kędziora-Kornatowska K. Quality of life for the chronically ill elderly. Gerontol Pol. 2016; 14(4): 185-189.

24. Gętek M, Nowakowska-Zajdel E, Czech N, et al. Quality of life of patients on dialysis and after renal transplantation. Ann Acad Med Siles. 2010; 64(5-6): 23-30.

25. Saffari M, Pakpour AH, Naderi MK, et al. Spiritual coping, religiosity and quality of life: a study on Muslim patients undergoing haemodialysis. Nephrology (Carlton). 2013; 18(4): 269-275, doi: 10.1111/nep.12041, indexed in Pubmed: 23432815.

26. Oliveira AP, Schmidt DB, Amatneeks TM, et al. Quality of life in hemodialysis patients and the relationship with mortality, hospitalizations and poor treatment adherence. J Bras Nefrol. 2016; 38(4): 411-420, doi: 10.5935/0101-2800.20160066, indexed in Pubmed: 28001183.

27. Md Yusop NB, Yoke Mun C, Shariff ZM, et al. Factors associated with quality of life among hemodialysis patients in Malaysia. PLoS One. 2013; 8(12): e84152, doi: 10.1371/journal.pone.0084152, indexed in Pubmed: 24358336

28. Feroze U, Noori N, Kovesdy C, et al. Quality-of-Life and Mortality in Hemodialysis Patients: Roles of Race and Nutritional Status. Clin J Am Soc Nephrol. 2011; 6(5): 1100-1111, doi: 10.2215/cjn.07690910.

29. Zyoud SH, Daraghmeh DN, Mezyed DO, et al. Factors affecting quality of life in patients on haemodialysis: a cross-sectional study from Palestine. BMC Nephrol. 2016; 17(1): 44, doi: 10.1186/s12882-016-0257-z, indexed in Pubmed: 27117687.

30. Hemati Z, Alidosti M, Sharifirad G, et al. The relationship between depression and quality of life among hemodialysis patients in Chaharmahal and Bakhtiari province in the year 2011. J Educ Health Promot. 2013; 2: 6, doi: 10.4103/2277-9531.106645, indexed in Pubmed: 24083256.

31. Drayer RA, Piraino B, Reynolds CF, et al. Characteristics of depression in hemodialysis patients: symptoms, quality of life and mortality risk. Gen Hosp Psychiatry. 2006; 28(4): 306-312, doi: 10.1016/j.genhosppsych.2006.03.008, indexed in Pubmed: 16814629.

32. Merom D, Sinnreich R, Aboudi V, et al. Lifestyle physical activity among urban Palestinians and Israelis: a cross-sectional comparison in the $\mathrm{Pa}$ lestinian-Israeli Jerusalem risk factor study. BMC Public Health. 2012; 12. 90 doi: 10.1186/1471-2458-12-90, indexed in Pubmed: 22289260

33. Lopes GB, Matos CM, Leite EB, et al. Depression as a potential explanation for gender differences in health-related quality of life among patients on maintenance hemodialysis. Nephron Clin Pract. 2010; 115(1): c35-c40, doi: 10.1159/000286348, indexed in Pubmed: 20173348.

34. Dudkowska D, Rumianowski B, Grochans E, et al. Comparison of the life quality of hemodialysis and peritoneal patients. Probl Hig Epidemiol. 2012; 93(3): 529-535.

35. Kao TW, Lai MS, Tsai TJ, et al. Economic, social, and psychological factors associated with health-related quality of life of chronic hemodialysis patients in northern Taiwan: a multicenter study. Artif Organs. 2009; 33(1): 61-68, doi: 10.1111/j.1525-1594.2008.00675.x, indexed in Pubmed: 19178442

36. Weisbord SD, Fried LF, Mor MK, et al. Renal provider recognition of symptoms in patients on maintenance hemodialysis. Clin J Am Soc Nephrol. 2007; 2(5): 960-967, doi: 10.2215/CJN.00990207, indexed in Pubmed: 17702730

37. Palmer BF, Clegg DJ, Palmer BF, et al. Sexual dysfunction in men and women with chronic kidney disease and end-stage kidney disease. Adv Ren Replace Ther. 2003; 10(1): 48-60, doi: 10.1053/jarr.2003.50003, indexed in Pubmed: 12616463.

38. Ersoy-Kart M, Guldii O. Vulnerability to stress, perceived social support, and coping styles among chronic hemodialysis. Dial Transplant. 2005. 